The Geneva Papers, 2012, 37, (1-4)

(C) 2012 The International Association for the Study of Insurance Economics 1018-5895/12 www.genevaassociation.org

\title{
Editorial
}

\section{Moving Insurance}

\author{
Patrick M. Liedtke \\ The Geneva Association, 53 Route de Malagnou, Geneva CH-1208, Switzerland. \\ E-mail: secretariat@genevaassociation.org
}

The Geneva Papers (2012) 37, 1-4. doi:10.1057/gpp.2011.35

The Geneva Association, or by its proper official name the International Association for the Study of Insurance Economics, was established in 1973 in Geneva, Switzerland, with the main aim to understand, study and appreciate the strategic implications for insurance of the changes in our societal, political, technological and financial environment. Professor Raymond Barre, first President of The Geneva Association and subsequently a Prime Minister of France, described the creation of the Association:

The Founders had realised that the evolution of insurance in contemporary economies and societies and at an international level called for an approach that was not restricted to a purely juridical vision of these activities. It was no longer enough to master the litigation aspect of relations between insurers and the insured. It was henceforth important for insurance companies to penetrate the complex world of risk and uncertainty and to design and implement strategies taking into account, not only the current economic, social and political forces and of the interests of their various partners: companies, consumers, financial institutions and the State, but also of the globalisations of economic and financial activities.

This is an excellent summary of the intent and spirit of The Geneva Association's founders, which still lives on today. As has become evident throughout the financial crisis, financial services are evolving rapidly and with them insurance activities. It is not only the markets that change, as well as the offering of products and solutions but the political and societal context in which this happens.

There are three areas that pose special challenges to the insurance sector at this juncture:

1. Real-world risks in a globalised economy: Escalating natural catastrophes, multiplying technological risks with always new ramifications and the challenges triggered by demographic risks. They all require proper attention, careful scrutiny, prudent risk pricing and reserving. In uncertain times, it is the strength of the insurance industry to be able to finance them-but they need to be financed through adequate premiums that reflect the true risks inherent to them. The challenge for the industry is to make sure we keep up with the many developments inherent in those risks and foreshadow future claims development. This is not made 
easier by increasing interconnectedness and more complex vulnerabilities of our systems (be they in the areas of nuclear, nanotech, IT or other technological areas). In addition, the business environment itself, with its manifold tools and processes, becomes more complicated and complex. Insurers need to make sure that they fully appreciate the extent of this development, the impact on the business and the resulting possible risk exposures that accompany this trend.

2. Regulatory risks: The financial crisis has acted as a wakeup call to all governments and institutions that had believed a loose steering of financial markets would be best. A flood of corrective action has ensued at national, regional and global levels to address already identified weaknesses of the regulatory and supervisory systems. This is resulting in the creation of a new global supervisory architecture for finance, directly changing the framework under which insurance companies operate. The challenge that the industry faces here is that such a massive and profound reorientation of the regulatory systems is happening in a relatively short period of time. The industry will have to make sure: (a) that it properly understands and appreciates the full extent of any regulatory changes; and (b) that it prepares the business to be compatible with them. The influence of, among others, Systemically Important Financial Institutions (SIFIs) designation discussions, new accounting norms, solvency regime reforms, etc. places a heavy weight on firms.

3. Financial risks in a new economic age: In the public sphere, financial markets are hard hit by the sovereign debt crisis and the question of what constitutes sustainable government debt in the long term. This is no small question, as insurers are not only among the largest institutional holders of government debt, but often a source of liquidity and buying power when many other sources do not function anymore. After all, one of the key lessons from the credit crisis was the resilience of the insurance sector and its continuing involvement in the capital markets around the world. However, it is precisely these markets that are today so nervous about their own future: enormous market uncertainty and volatility are coupled with doubts about future long-term growth, not least influenced by historically unprecedented demographic developments - a prolonged shrinking and ageing of the population - in most developed and many developing countries. It will not be easy for the industry to steer through the treacherous waters of a sovereign debt crisis that has put any notion of "risk-free assets" to rest and that no longer provides a truly safe haven to investors. Investment policies in the face of a more volatile and uncertain environment with less secure investment options will have to look and operate differently than in the past. At the same time, insurance mechanisms need first and foremost to be able to secure ready and predictable access to funds in the case of claims. It is this mechanism that is at the very base of the societal role of the insurance industry and that is providing policyholders with peace of mind all around the world. Yet it is precisely this ready and predictable access that is being made so much more demanding in the new environment.

The Geneva Papers on Risk and Insurance-Issues and Practice has a history of collecting and publishing articles that provide insights into key issues facing the insurance industry. At the start of a new year, 2012, and looking at the first issue of 
volume 37 , it is very reassuring to see how many different facets are covered by so many eminent authors, who all have won the respect and approval of their peers through a demanding review process, and in the case of the two award-winning papers of The Geneva Association/IIS Shin Research Excellence Awards, convinced an international jury of prominent experts following a highly competitive selection process.

$$
* * * * *
$$

The following pages offer eight contributions on a wide variety of essential subjects in insurance and the economy by large, including papers on life insurance markets, regulation, price discrimination and microinsurance. This volume starts with an article by Carolin Hecht and Katja Hanewald on Who Responds to Tax Reforms? Evidence from the Life Insurance Market. The paper analyses socio-demographic, economic and psychological household characteristics elicited in the German SAVE study, on the effects of tax incentives on consumer behaviour in life insurance markets. It shows that education plays a central role in reactions to the modified tax environment. The issue then moves on to Non-Risk Price Discrimination in Insurance: Market Outcomes and Public Policy, by R. Guy Thomas. The paper considers price discrimination in insurance; an analysis is given of one type of price discrimination, called "inertia pricing", where renewal prices are higher than prices for risk-equivalent new customers. The analysis suggests that the practice intensifies competition, leading to lower aggregate industry profits. Customers in aggregate pay lower prices, but not all customers are better off, and the high level of switching between insurers is inefficient for society as a whole. The third paper, by Anja Theis and Michael Wolgast, investigates Regulation and Reform of Rating Agencies in the European Union: An Insurance Industry Perspective. The investigation of the current discussion on the regulatory framework for credit rating agencies from the perspective of the insurance industry, focusing on the European Union, shows that the new European system of regulation and supervision conforms well to general principles of economic theory and can be expected to resolve many issues of concern. However, some additional policy options being discussed could involve additional costs and risks for market participants, without really contributing to the objectives of these reforms. The following paper, on Insurability in Microinsurance Markets: An Analysis of Problems and Potential Solutions, by Christian Biener and Martin Eling, aims at enhancing the understanding of impediments to and facilitators of microinsurance from an economic perspective and outlines potential solutions to these issues. The penultimate article in this first section covers Governance and Shareholder Response to Chief Risk Officer Appointments. It is written by Manu Gupta, Puneet Prakash and Nanda Rangan, and it examines the recent, significant growth in the appointments of Chief Risk Officers, their role, and whether such appointments benefit shareholders. The last article in this section, Globalisation and Convergence of International Life Insurance Markets, by Chien-Chiang Lee and Chi-Hung Chang, empirically examines the influence of the KOF index of globalisation on the development and convergence of international life insurance markets by a panel cointegration technique. The main conclusion is that globalisation has a significant impact on the development of 
international life insurance penetration and the world average, and that economic and social dimensions exert similar effects.

The final section of this issue showcases the two award-winning papers of The Geneva Association/IIS Shin Research Excellence Awards, focusing on the topics of insurance and regulation today. The first article, written by Mary Kelly, Anne Kleffner and Darrell Leadbetter, deals with Structure, Principles and Effectiveness of Insurance Regulation in the 21st Century: Insights from Canada. Canada was one of the rare countries that did not have to provide financial support to distressed financial institutions during the 2007-2009 financial crisis. By examining the elements of the Canadian regulatory framework that contributed to the success of the insurance industry in weathering the crisis, and comparing it to that of other jurisdictions, lessons were drawn and portrayed in this article. The other award-winning paper, by Robert W. Klein, is on Principles for Insurance Regulation: An Evaluation of Current Practices and Potential Reforms. Subsequent to the recent financial crisis, the potential vulnerability of insurance companies to systemic risk has been of increasing interest to policymakers and regulators. In this context, this paper examines the basic economic principles that should govern the regulation of insurance and employs these principles in assessing current regulatory practices and potential reforms. 